\title{
Analysis of the Response Mechanism of College Student Education Management in the New Media Environment
}

\section{Weili Ding}

Zhoukou Normal University, Zhoukou, Henan, 466000

Author profile: Ding Weili, female, January 1984, native of Luyi County, Henan Province, Han Nationality, Zhoukou Normal University, postgraduate, teaching assistant, instructor

\begin{abstract}
The continuous improvement of Internet technology has ushered in the era of new media. At the same time, various new media technologies have also brought important effects on different industries. Therefore, colleges and universities need to keep abreast of the development requirements of the times when conducting student education management work, and be able to find effective response mechanisms in the ever-changing new media environment. This article starts from multiple angles and explores the specific ways of higher education management under the background of new media, hoping to provide valuable management experience for other school education management staff.
\end{abstract}

Keywords: Response mechanism; higher education; new media environment; education management

Traditional education management work has been difficult to integrate with the ever-changing new media environment. Therefore, many colleges and universities have combined with the development requirements of the times, and after specific analysis of the overall behavioral awareness, speculative thinking and value concept of college students, they are targeted To innovate in education management. This requires schools to actively conduct in-depth analysis of the current goals of cultivating talents in higher education institutions, and improve their own educational management work content in accordance with the new environment and new current situation. This can not only cultivate outstanding talents with high literacy, but also enable students to cultivate talents who can shoulder the development requirements of the new era while meeting the requirements of social post development. Therefore, how to grasp the development context of the new media era and effectively improve the current education management work is the main research issue of this article.

\section{Innovate management concepts in time and improve service management mechanisms}

Excellent school administrators should promptly innovate their management concepts in accordance with the development requirements of the times. Therefore, it is necessary for the education management personnel of colleges and universities to pay attention to the importance of new media technology to the development of different industries and actively change the perspective of backward student education management in combination with the existing school conditions. Because college students are active in their thinking and have strong thinking ability. Therefore, many students are very close to the new media. Students can not only use new media technology to integrate the required learning resources, but also enable themselves under the guidance of new media technology to ensure their learning enthusiasm and generate motivation to actively complete knowledge learning.

This requires school administrators to carefully analyze the advantages brought by the new media environment and

Copyright (C) 2020 Weili Ding

doi: $10.18282 /$ le.v9i6.1282

This is an open-access article distributed under the terms of the Creative Commons Attribution Non-Commercial License

(http://creativecommons.org/licenses/by-nc/4.0/), which permits unrestricted non-commercial use, distribution, and reproduction in any medium, provided the original work is properly cited. 
actively innovate management concepts, so as to continuously improve the educational form and management content, and at the same time guide students to actively participate in the learning activities of the school. Reasonable planning for development prospects will ensure a rapid rise in the level of education management in the process of enabling both parties to communicate better through the use of new media technologies. Therefore, education managers need to be able to use new media technology to improve the school's service management mechanism under the guidance of the student-oriented view, and to meet the needs of students' learning as the primary management content. This can not only prevent students from being affected by bad information in the majestic Internet era, their own values, and the education management system with service as the goal can also better help managers to proceed from the actual situation to the overall education work Perfect, so as to achieve the purpose of effectively improving the management level.

\section{Expand management ideas and establish a new media communication platform}

With the continuous change and development of the times, the emergence of new media has effectively enriched the channels for people to obtain information. Therefore, when many students participate in learning activities, they will choose to use new media technology to find information retrieval methods that meet their own learning needs, and have an important impact on their own cognitive characteristics. Many students tend to pay more attention to the diversity of media technology, the timeliness of retrieval, and the simplicity of content when searching for learning materials. Therefore, educational management personnel in higher education institutions also need to expand their management thinking through specific analysis of students' actual cognitive characteristics and individualized development. Therefore, in the new media environment, education management staff should firmly grasp the value orientation of students and ensure that the content of education management work can meet the realistic requirements of students.

In addition, the traditional education management model has severely severed the relationship between teachers and students, causing the two parties to gradually distance themselves from each other while seriously affecting the smooth progress of management. In the new media environment, managers and students can ensure effective communication, so that managers no longer appear in a serious management image, but in more harmonious interaction and equal communication with students, so that both parties can work together to complete the exchange. The innovation of the content of education management work, and then achieve the purpose of promoting better development of education management work. Therefore, college education managers should be able to establish a network interactive platform through the use of technology in a new media environment, and push various industry public opinion trends, real-time information, network public opinion and other content to students in a timely manner, so as to prevent students from making mistakes. Going astray in the information environment. At the same time, a more efficient information exchange platform can also enable teachers and students to strengthen the connection, and at the same time, to better improve the students' values, dominant awareness and thinking ability, so as to train students in the process of establishing correct views of right and wrong and life concepts., So that students get all-round development. This can not only ensure the smooth progress of education management, but also enable higher education institutions to develop better in the everevolving tide of the times with the blessing of new media technology.

\section{Concluding remarks}

The continuous innovation of new media technology has made many colleges and universities inject more vitality into the process of student education management. At the same time, many colleges and universities have ushered in many challenges in the wave of constant change and development. . This requires schools to grasp the individual needs and development characteristics of college students, and introduce them into educational management activities through the use of new media technologies. This can not only break through the shackles of the outdated education management model, but also further strengthen the interaction and communication with students, and at the same time, from different angles, better maintain the personalized development of students, so as to create a good learning environment for them, Promote the high-quality completion of education management. 


\section{References}

1. Zhang Xuan, Shang Dan, Li Haoran. Analysis of the educational management path of ethnic students in inland colleges from the perspective of the consciousness of the Chinese nation community_-Taking the educational practice of Guangzhou G University to forge the consciousness of the Chinese nation community as an example[J]. Hubei Journal of Open Vocational College, 2020, 33(12): 80-82.

2. Sun Lirui, Bian Xueyu, Liu Bowen. Innovative research on student affairs work in colleges and universities under the Internet environment: Taking the education and management of 2017 students in the School of Microelectronics of Xidian University as an example [J]. High Education Journal, 2020(14): 32 -34+39.

3. Alida Onhalbai. Research on the education and management of ethnic minority students in inland universities [C]. Wuhan Chuangdu Times Publishing and Planning Co., Ltd. Jingchu Academic (February 2020). Wuhan Chuangxin Reading Times Publishing Planning Co., Ltd.: Wuhan Chuangdu Times Publishing Planning Co., Ltd., 2020: 29. 